Preprint. Final version available as:

ATTFIELD S., FEGAN, S. \& BLANDFORD, A. (2008) Idea Generation and Material Consolidation: Tool Use and Intermediate Artefacts in a Case Study of Journalistic Writing. Cognition, Technology \& Work. DOI http://dx.doi.org/10.1007/s10111-008-0111-6

\title{
Idea Generation and Material Consolidation: Tool Use and Intermediate Artefacts in Case Study of Journalistic Writing
}

Simon Attfield, UCL Interaction Centre, University College London. s.attfield@cs.ucl.ac.uk, +44 (0) 2076795242 (tel), +44 (0) 2076795295 (fax).

Ann Blandford, UCL Interaction Centre, University College London.

Sarah Fegan, John Lewis, London

\begin{abstract}
We report an in-depth, longitudinal study of a freelance music journalist writing a feature article. Our analysis attends to the participant's activities from initiation to completion, and the ways in which she established structure using tools and artefacts to support cognitive effort. We observed five work stages: establishing an initial idea; preparing for an interview; interviewing; planning the article; and writing. Each resulted in the production of a working document embodying ideas and commitments which provided a key resource for the next stage. Stages began with phases of idea generation during which ideas were spontaneously triggered through intense engagement with information resources. They finished with phases of material consolidation when intermediate artifacts were configured to facilitate generation during the next stage. We examine these in detail and use our findings to motivate a discussion of working document overview representations and specific requirements related to idea generation and material consolidation.
\end{abstract}

Keywords: Information Behaviour, Field Study, Writing, Journalism.

This work was in part funded by EPSRC grant EP/D056268 ('Making Sense of Information') 
2 Simon Attfield, UCL Interaction Centre, University College London.

s.attfield@cs.ucl.ac.uk, +44 (0) 2076795242 (tel), +44 (0) 2076795295 (fax).

\section{INTRODUCTION}

There has been a long interest in increasing the productivity of writing through improved tools. To date, however, most research and electronic writing tools of note (e.g. word processors, hypertext authoring tools and collaborative writing environments) have focused on the text production aspects of writing to the exclusion of other equality important aspects of the process (O'Hara et al 2002).

Creating a document is kind of design activity (Goel \& Pirolli 1992, Sharples 1996). It is frequently complex, extends over time, and can involve multiple activities such as researching, storing and manipulating information, recording ideas, planning and experimenting (O'Hara et al 2002). Understanding and supporting these is as important as supporting the writing itself. In common with many cognitively demanding tasks, during document production people actively and dynamically construct and manipulate their environments to better support their work. By understanding what people do and how it helps them, we can better understand how to design systems to support such complex activities.

We report an in-depth case study of a freelance music journalist researching and writing a feature article for a national Sunday supplement which took place over a period of about three weeks. This case study has taken an idiographic approach (Luthans \& Davis 1982) to research, in which a single case study is investigated in depth in order to develop a good understanding of the context in which work takes place and the roles that tools and artefacts play in supporting (or hindering) that work. As Luthans and Davis (1982) argue, this approach provides a useful complement to the more common nomothetic approach that seeks to generalize across many cases, resulting in accounts of behaviour that are presented at a level of abstraction such that many of the important individual details are lost.

The questions addressed in this paper are: what are the activities, how do they interrelate, what are the main artefacts that are generated and used, and how do they support these activities?

Our study extends on previous work of this type, such as that of O'Hara et al (2002) on the use of source documents during writing, to consider the lifecycle of an extended research and writing task from initiation to completion. In this sense, the current paper aims to supplement that earlier study work by extending the unit of analysis to the entire lifecycle of a writing assignment.

We begin with a discussion of background literature. We then report the method of the study and present and discuss our findings. Finally, we relate the findings to the design of tools to support this kind of writing activity.

\section{BACKGROUND}

Since the work reported here is concerned with both writing and with design, we discuss research in both areas. 
Idea Generation and Material Consolidation: Tool Use and Intermediate Artefacts in Case Study of Journalistic Writing 3

\section{Writing}

Within the psychological literature, there have been some accounts of the writing process, including the work of Bereiter and Scardamalia (1987) and Flower and Hayes (1981). Of these, the model by Flower and Hayes is probably best known; it describes the internal cognitive processes involved in expository writing. At the highest level of abstraction, this model divides the writer's world into the task environment (i.e. topic, intended audience, motivation and the text produced so far), long-term memory and the writing process. The writing process is viewed as the interaction between three broad cognitive sub-processes: planning, translating and reviewing. Planning develops the writing plan (and sets goals); translating converts this plan into text; and reviewing involves reading the text and editing. Within this, generating is a sub-process of planning which retrieves information from long-term memory, including topic information or writing knowledge. The model proceeds through the firing of production rules. One aim of the model is to use different goalsetting production rules to account for variations in the way people approach writing tasks (e.g. get it down as you think then review, perfect first draft etc).

Flower and Hayes' model points to the significance of the task environment in terms of influencing writing processes, but they do not consider how external tools and media, and manipulations to these, facilitate, influence and affect writing ( $\mathrm{O}^{\prime} \mathrm{Hara}$ et al 2002, Haas, 1996). For this reason Haas (1996) argues that the model buys into the "transparency myth" and ignores the impact of technology on writing. Sharples (1996 p11) reiterates this criticism, arguing that "a cognitive model of writing is concerned primarily with the writer as a thinker and a problem solver. It does not address such questions as: What purpose is served by written notes, plans and outlines? Why do writers prefer one tool over another? Which types of media are suited to which writing tasks?" Sharples draws particular attention to the creation of external representations, arguing that these enable the writer to explore different ways of structuring content and to apply systematic transformations, such as prioritising, reversing order, or clustering related items. In Sharples' terms, "Writing creates external representations and the external representations condition the writing process" (Sharples $1996 \mathrm{p} 8$ ).

Important questions revolve around how external tools and media might be designed in a way that better supports the task. There has been some valuable research into computer-based writing tools, their attributes, and the effect they have on writing performance. Haas et al (Haas 1989, Haas 1996, Hansen \& Haas 1988), for example, have highlighted differences in speed, quality and process between different computers, other tools and paper. Findings from these studies showed that greater planning times were needed when writing with pen and paper, and more extensive rereading and text revision were done on the computer.

Extending the focus beyond text production tools, a number of researchers have developed electronic tools for supporting external representations that may be created and used during writing. Neuwirth and Kaufer (1989), for example, developed a task framework for composing a written document from source materials which consisted of:

- Identifying relevant information in individual source texts. 
4 Simon Attfield, UCL Interaction Centre, University College London.

s.attfield@cs.ucl.ac.uk, +44 (0) 2076795242 (tel), +44 (0) 2076795295 (fax).

- Grouping sources by similarities and differences.

- Organising sources into a tree by similarity /difference.

- Generating document structure by traversing the previously developed hierarchy.

From this, they identified external representations that might facilitate the process and developed a set of tools to support them. The heuristics they used as a guide to design included: minimise the effort needed to encode external representations into internal understanding; support and reduce memory effort; and direct cognition and attention through the tasks. A similar framework was adopted by Smith et al (1987) in the design of a hypertext writing environment in which information can be organised hierarchically then written into a sequence by traversing the tree.

In order to understand how such external tools and media might be designed to support users during writing tasks, though, it is necessary to observe the way writers naturally produce, adapt and coordinate external artefacts. With this in mind, O'Hara et al (O'Hara et al 2002) reported a study of the way in which writers used source documents during everyday writing tasks. Recognising the limitations of a purely cognitive perspective, they focussed on interactions in terms of the material properties of source documents and how these relate to underlying cognitive processes.

Among their findings, they reported periods of frequent attentional shift between source documents and composition for quick reference, and that participants often noted the spatial location of information in source documents with a finger or annotation. They also noted that participants spread documents out on their desks in a way that reflected task or content structure in order to make the information visually available (exploiting properties such as colour or size) without sacrificing visibility of the composition. This spatial layout could change many times as different source documents became the focus of attention. O'Hara et al (2002) concluded with recommendations for writing systems, such as multiple display surfaces, maintaining fixity of information with respect to key physical features on a page, and allowing windows to be shuffled and sorted like paper documents.

\section{Design}

Design activities are complex, unpredictable, and consequently difficult to characterise. To make sense of this complexity, some researchers have drawn attention to seemingly generalisable attributes which are persistent across domains. For example, a number of researchers have highlighted the importance of experimentation. Schön (1983) proposed that a dynamic of experimentation and reflection, or "a reflective conversation with the situation", is at the heart of all design professions. The designer engages in a continual process of move making, reviewing the situation to assess the result, and moving again. Lawson (1997) refers to similar process of "analysis through synthesis", which places particular emphasis on the idea of learning through experimentation.

These perspectives both point to the importance of developing external representations in order to characterise partial solution ideas as a source for reflection, as well as a means of communication (Hewitt, 2005). In the context of writing, Sharples (1996) argues that the value of putting such ideas down on paper (or some 
Idea Generation and Material Consolidation: Tool Use and Intermediate Artefacts in Case Study of Journalistic Writing 5

other suitable medium) is to offload computational effort, leaving the writer free to explore different ways of structuring content and to apply transformations, such as prioritisation or clustering of related items.

Experimentation, of course, implies evaluation. During problem-solving, designers iteratively elaborate and evaluate solutions with respect to various criteria and constraints (Bonnardel 1999). Lawson (1997) emphasised the way in which designers discover more about the problem as they critically evaluate their own solutions, and the need to support such evaluation features in Shneiderman's revised four-phase framework outlining the idea of the 'genex' (standing for generator of excellence). This framework is a high-level conceptual outline of activities which he argues are key to creativity (viz. collect, relate, create, donate), and are therefore important to support through design (Shneiderman 2000).

Some studies have illustrated the way that designers create and use multiple, intermediate representations of products (e.g. Sumner \& Stolze 1997, Belotti \& Rogers 1997, Newman \& Landay 2000). For example, Newman and Landay (2000) report on the various process stages and associated intermediate representational artifacts created and used in the course of professional Web designers. They showed how, during design, a website is represented through a range of intermediate artifacts each embodying different kinds of commitments; these include maps, storyboards, schematics, mock-ups and prototypes.

In particular, Newman and Landay draw identify a contrast between low-fidelity, early design representations, which focus on representing structure and navigation, and later representations which are high-fidelity and aesthetically oriented. They show how these representations are central in the communication of design ideas and options, and achieving consensus and instilling confidence, for example, during the client meetings that punctuate the design process.

As well as representing solutions and partial solutions, external representations are also important for representing domain information. This is particularly pertinent within knowledge work (and formed a central focus in O'Hara et al (2002), since a central part of knowledge tasks is the reconfiguration of domain information into a new artefact. With this in mind, Shneiderman $(1999,2000)$ includes visualizing data within his explication of the genex framework. Hewitt (2005) similarly points out that the domains of creative work that have been studied generally involve sorting and identifying constituents that will ultimately become part of a creative product.

In summary, the inadequacies of purely cognitive accounts of writing, in terms of the analysis of the role of external artefacts, have given rise to an interest in how the properties of such artefacts can condition and support the writing process. Such accounts are of particular interest to Human Computer Interaction since they concern the tools and representations that people use in order to be effective. Work in this area has concerned comparisons between computer and non-computer writing tools, and tools for intermediate representations, as well as more ethnographic work looking at the resources that writers use in action. However, these accounts have so far been limited insofar as the unit of analysis has been limited to the point of writing.

Within work related to design in general, we have drawn attention to some general characteristics of processes, such as iterative cycles of experimentation and reflection; the generation of interim representations; the associated need for evaluation; and the 
6 Simon Attfield, UCL Interaction Centre, University College London.

s.attfield@cs.ucl.ac.uk, +44 (0) 2076795242 (tel), +44 (0) 2076795295 (fax).

use of external representations of domain information. Our aim in this study was to explore some specifics of interim, external representation creation and use, and to draw from these similar generalised patterns of activity.

\section{METHOD}

An initial orientation interview conducted with the participant provided a formative understanding of the process of producing a feature article. This guided subsequent data gathering based on the idea of theoretical sampling (Glaser \& Strauss 1967). Six observation sessions and follow-up interviews were conducted at different points in the feature writing lifecycle.

Sessions lasted two to three hours and focused on observing activities and related artefacts. Several tasks were observed twice. The only part of the process that we were unable to observe was an interview with the artist who was the subject of the article, although the participant verbally reported this to us.

During the visits, extensive time-stamped field notes were taken, a total of seven hours video data of the participant working recorded, and key working documents were collected. After each observation, a debrief interview was conducted with the participant, lasting about 40 minutes. Questions focused on understanding the participant's thoughts and reasons for behaviour. All interviews were audio recorded.

Following each visit, the interview was transcribed, and field-notes, video data, and working documents were cross-referenced using the time-stamps and visual information.

Our interest in interim artefacts (or working documents), and the ways in which properties were designed into them to support cognitive processes, aligns this study within the general framework of Distributed Cognition (Hollan et al 2000). Distributed Cognition views cognitive representations and processes (such as memory, for example) as distributed between people and artefacts. It engages directly with the idea that artefacts and their properties impact in important ways, and even form a part of cognitive processes. Following Hollan et al (2000), our approach to data gathering and analysis attended to phenomena where the participant established, coordinated and maintained structure within, or off-loaded cognitive effort to the environment.

\section{FINDINGS}

The journalist worked from home, writing feature articles for music publications. Features tended to be between 1400 to 2000 words and focused on artists who had recently released new recordings. Central to a feature would be an interview with the musician. Writing a feature involved approximately four day's work which could extend over a two to three week period. The participant tended to have several assignments on the go at any one time. 
Idea Generation and Material Consolidation: Tool Use and Intermediate Artefacts in Case Study of Journalistic Writing 7

Analysis of the assignment lifecycle revealed a sequence of five stages: establishing an initial idea; preparing for the interview; interviewing; planning the article; and writing. Each stage resulted in the production of a working document which then became a key resource for a subsequent stage. The contingencies between documents and processes are shown in figure 1 .

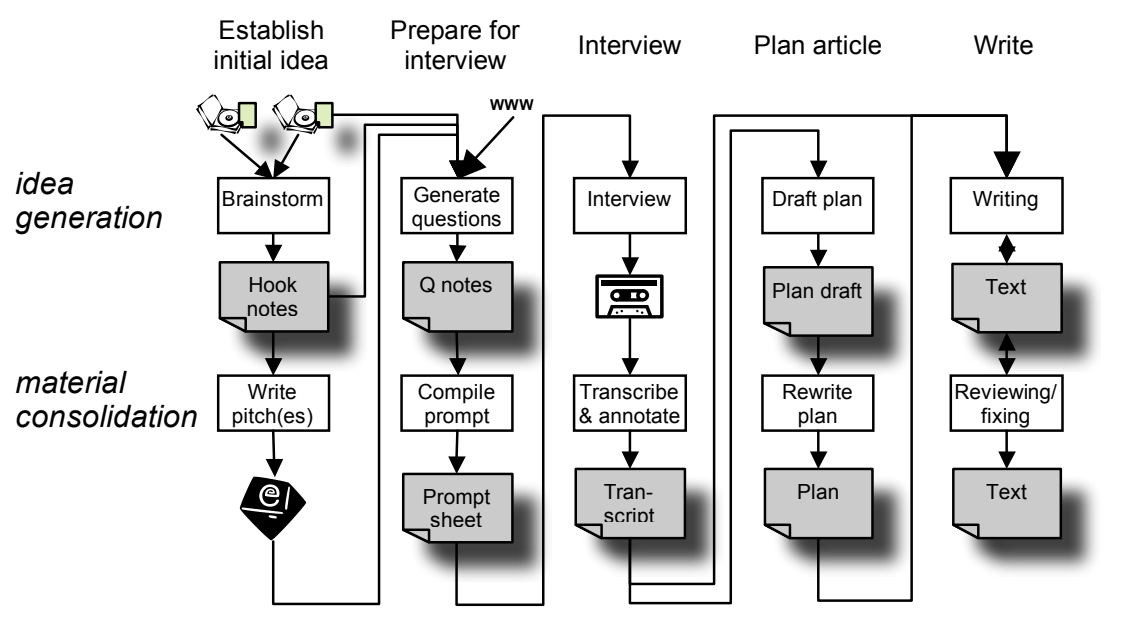

Figure 1. the five stages of the journalists work showing phases of idea generation and material consolidation and the working documents produced and used by each.

Further, each stage began with activities that were characteristically intense and generative (i.e. new ideas or data were created) and gave rise to content for the artefact. We refer to this as the idea generation phase. Each stage then finished with activities which were characteristically consolidatory (i.e. ideas or data that had been generated were integrated into a working document). We refer to this as the material consolidation phase. It was during these phases that the participant paid attention to establishing the necessary properties of each working document such that it would optimally support cognition during the next phase of idea generation.

In the following, we describe each stage in turn and how it gave rise to and exploited structured material artefacts.

\section{Establishing an initial idea}

The participant's first task was to decide on a set of feature ideas and to pitch these to an editor with whom she would agree a commission. She received several press releases about bands with accompanying CDs in her post each day, and would routinely skim through these in order to identify suitable foci for a feature. Her 
8 Simon Attfield, UCL Interaction Centre, University College London.

s.attfield@cs.ucl.ac.uk, +44 (0) 2076795242 (tel), +44 (0) 2076795295 (fax).

filtering criteria included: her interest in the music; the relationship between the album release date and her available writing time; and the extent to which the material suggested a 'hook' (a key idea which will become the central focus of a piece). Sometimes she would also explore a band's website or an online music database for more information.

She recorded her filtering decisions by creating two piles of press material: a pile that she planned to attend to further, and a pile for filing. The former was placed in a prominent position near her desk as a reminder for further action.

"That (pile) is kind of stuff I might be interested in, I keep that there (on the sofa next to the desk) just so I don't forget about it."

Later, the participant would generate and record feature ideas by performing a more detailed review of material in the 'interesting' pile. For each band, she would listen to the $\mathrm{CD}$ whilst reading the press release material and making rough notes in an email about a possible hook:

"I see if there is a hook in there like 'band of three brothers, toured America when they were little, are now again on the road' - the fact they were three brothers is a hook"

At this stage she may also contact people to check availability of the band for interview.

Once her notes were made, the participant would package each feature idea into a one-paragraph persuasive pitch that she would send to her editor. Following a further telephone conversation, the editor would confirm his/her choice by email. The participant would then place the press material relating to the commission on her desk where they were to hand.

\section{Discussion}

The filtering and selection of material has been previously documented (e.g. Hewitt, 2005) in the context of identifying building blocks for an article; in this case study, we see a different use of the filtered material - namely for generating a single, fundamental starting point for the work. Consequently, for our participant, filtering played a central role in determining a potential solution space. She was looking for opportunities from which to begin constructing a solution.

Filtering information sources in search of ideas for the creation of a new information artefact is typical of many writing assignments. Attfield et al (2003) analyse such filtering decisions to illustrate how monitoring information sources (their example is of a news journalist) can trigger an initial idea for an assignment. According to their analysis, multiple constraints each independently define a solution space, and intersections define spaces for 'ideal', integrated solutions. The constraints may vary from situation to situation, but the structure of the activity is the same. The current example, however, emphasises how filtering can be simultaneously evaluative and generative. Source materials were used to generate potential ideas for feature articles, and it was these ideas that were subject to the evaluation.

The objective of this first stage was to develop a set of 'pitches'; as such these formed the working document output. The distinction between idea generation and 
Idea Generation and Material Consolidation: Tool Use and Intermediate Artefacts in Case Study of Journalistic Writing 9

material consolidation shows itself between the initial two-pass engagement with the source material and subsequent integration of ideas. During the generation phase, engagement with the source material became increasingly intense as 'inspiration' was sought and new ideas were evoked and recorded. The participant immersed herself in the material which she distributed physically to support high visibility and the means of recording ideas was simple.

Attention to the presentation of ideas was deferred until the final phase of consolidating the ideas into the pitches, when she focused on developing the persuasive quality of the ideas. Apparently, no new ideas occurred at this point, but existing ideas were honed and formatted for communication so that the final selection could be made by the editor.

In the consolidation phase, tools were needed to hone material into presentable format for transmission to the editor: transparency of tools was less important in favour of the availability of features to support the clear structuring of text.

\section{Preparing for the interview}

Once a feature idea had been agreed, the participant would prepare for an interview with the artist by generating a set of potential questions. She listened to the CD carefully several times whilst reading the press material, websites, previous press articles, etc. in detail. This detailed exploration of the material was used to inspire questions. These tended to arise in bursts and were jotted down onto paper or word processor (depending on what was to hand). At this time the participant's attention was predominantly focused on the source materials, and concern was not given to the coherence or structure of the question set:

“When I'm focusing on writing questions I read it (the biography) quite heavily and every sentence can potentially raise a question. You could cast you eye over it and not see much at all, but really thinking about it and focusing on trying to work out anything else"

"When brainstorming I'll write the same question twice, maybe in 2 different ways without realising [...] it's just really what comes off the top of my head [...]. There is no concern about getting the words right"

To generate questions, the participant described using the source materials to create theories about the artists. Questions would then test these theories:

"Yeah but I need to have a theory for questions. [...] It's what's prompting me with my questions. I have to have a theory."

The participant viewed all documents in full screen, and switched between documents by minimising and maximizing windows. She expressed frustration with the time and effort this entailed. To mitigate against interruptions to her flow of thought when brainstorming questions, she occasionally cut and pasted sections from source documents into her questions document, used them to inspire interview questions, and then deleted them. 
10 Simon Attfield, UCL Interaction Centre, University College London.

s.attfield@cs.ucl.ac.uk, +44 (0) 2076795242 (tel), +44 (0) 2076795295 (fax).

Throughout the observation, the participant frequently switched to other tasks, such as checking email and writing a letter. During these interruptions she would rearrange documents on her desk to bring those most relevant to a new task closer. This, she reported, prompted her with where she had got to on the other tasks.

After brainstorming questions, the participant would then use the notes she had created to compile a question sheet which would act as a prompt during the interview. This involved typing the questions into a word processor, and as she did, formatting those questions she considered particularly important in bold to make them visually distinct. She also edited the set down to a single page, with each question on a single line for portability and readability. She also grouped the questions by theme and ordered them into a possible conversation flow. Editing the questions into this structure could also prompt more questions to ask.

\section{Discussion}

Preparing for interview also has two distinct phases. The first, brainstorming questions, was characteristically generative, with new ideas, or 'theories' being sought. To trigger these ideas, the participant once again immersed herself in the source materials. Indeed, each time she interacted with the source materials she did so with apparently increasing levels of engagement. During bursts of brainstorming, maintaining attentional flow appeared paramount, and may explain the selective separation of concerns across two phases of work. The separation indicates the need to align cognitive resources around one type of concern in order to be most effective.

The brainstorming phase also featured the coordination of different source materials with each other, and with the evolving questions, and the need to minimize the interruptions of doing so. This is consistent with O'Hara et al's (2002) observations of people during everyday writing tasks. In the current study, not only did the interruptions necessitated by managing attentional shifts between documents using a computer cause frustration: the journalist also employed strategies to reduce their impact (e.g. copying and pasting into a single document).

Generation, in particular highlights requirements to better support easy overview of multiple documents and smooth transfer of text from one document to another. In addition, other tasks were interleaved with the focus task: these pauses supported reflection and review, and required easy restructuring of artefacts in the workspace.

The working document produced during interview preparation was a single sheet of questions and the second phase involved consolidating the products of the previous idea generation. As in the previous stage of work, selective disregard for coherence and formatting during the initial phase gave way to a focus on these in the second. The specific aim in the material consolidation phase was the structuring of a resource that would optimally support the needs of the next stage-interviewing.

\section{Interviewing}

The interview was to provide a key source of information, and was audio recoded. The participant conducted interviews as conversations. As such, her question sheet 
Idea Generation and Material Consolidation: Tool Use and Intermediate Artefacts in Case Study of Journalistic Writing 11

acted only as an occasional prompt, rather than as a script; questions could be omitted and unplanned questions might be asked.

"If they say something interesting then I'm going to follow it up with "why did you say that" or "why did you feel that" even if it's not in my questions that's where you get your best information."

Occasionally the participant would annotate her questions sheet during an interview with additional questions that came to mind. Following the interview, she also made additional brief shorthand notes in a small, unobtrusive notebook.

Consolidating the interview material involved transcribing the audio recording. This was done in order to support non-linear reviewing in the next stage of work. Within the transcript, she highlighted questions in bold and then printed and stapled the transcript for easy physical reference.

Researcher: "You always print that out?"

Participant: "Yeah it's really important: it's such as huge document you can't be flicking it on the computer, it's a couple of pages long and you really do need to have access to it right next to where you can see it."

The participant's approach to writing a feature was to weave quotations (perhaps paraphrased) together into a story. Before writing a plan, she would prepare the transcript by reading it carefully and underlining interesting quotations in colour to draw her attention (see Figure 2 for an example).

"Again just to draw your eye to it, you've got a whole page of words...the fact I underline it just helps me to find it quicker."

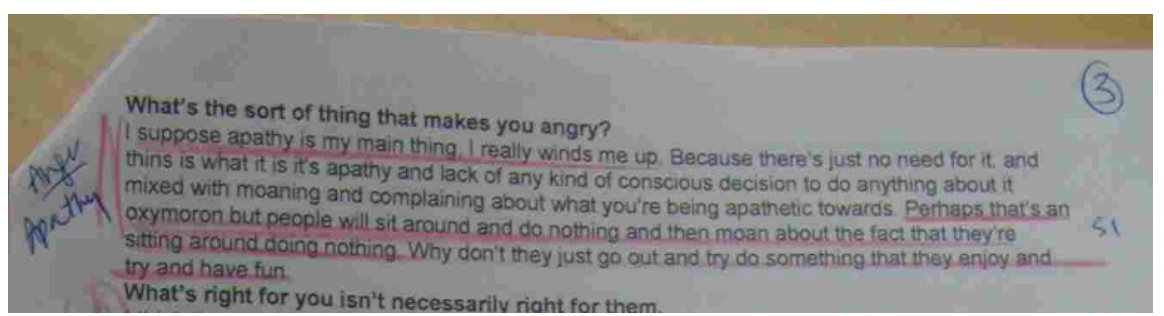

Figure 2. An interview transcript with quotations underlined, themes identified and quotations and pages numbered.

She would also number selected quotations so that they could be included in the plan by reference, rather than having to reproduce them verbatim.

The participant would also annotate the transcript margin to indicate the main theme of each section. This acted as an index into the content and promoted familiarity with the transcript structure. This ensured that it could be reviewed easily, and without disrupting the flow of writing, even if this hadn't been planned for: 
12 Simon Attfield, UCL Interaction Centre, University College London.

s.attfield@cs.ucl.ac.uk, +44 (0) 2076795242 (tel), +44 (0) 2076795295 (fax).

\begin{abstract}
"Sometimes, when I come to write the piece, even though on my plan I've not mentioned something, then I'll then decide "Ah yeah! That will be really good there" and I kind of know where it is. It's the same page as that. Then I use a quote that I'm not actually meant to use.... which is why it's such as visual thing for me, it's why I annotated and highlighted quotes. It's about reference as well."
\end{abstract}

\title{
Discussion
}

Like previous stages, conducting the interview and its transcription phase shows the pattern of generation followed by material consolidation. During the interview the question sheet provided a prompt, but despite fairly intense prior preparation of the sheet, this was only used occasionally: the sheet preparation served more as a rehearsal mechanism than an active prompt in the interview. The flow of the interview was more important and the journalist was open to new ideas and issues that might arise. Like earlier generation phases, enabling the flow of thoughts (or conversation) during the interview had priority. The methods used for capturing information (i.e. audio recording and unobtrusive notebook) are concerned with capturing content in a way that supports this flow without concern being given to format or structure.

The working document produced by the interview stage is the annotated transcript. Transcribing, printing and annotating the transcript, including quotation underlining and numbering and thematic indexing, was time consuming, detailed and precise. And like previous stages the aim in the consolidation phase is to format the interview content into a resource which anticipated the demands of subsequent stages of work.

The transcription and annotation of the interview highlight the need for tools that better support document overview and detailed reviewing and annotation in a way that will more directly feed in to the next stage of article preparation, namely planning the article.

\section{Planning the article}

Once the journalist had created the annotated transcript, the next step was to write a plan for the article. The role of the plan was to set out key ideas as a coherent series. The plan was largely written in chronological order, with the beginning and ending sometimes left open to develop during writing.

In order to begin the plan, the participant would read through the transcript carefully, looking for inspiration on how the piece might begin. Generating the plan was described as finding a 'route' that would link up important ideas. Journey metaphors were used extensively by the participant. For example, the plan was said to act as a kind of 'map', and separate ideas acted as way-marks to be 'visited' by the plan:

"I try and work out the direction I'm going to go. Say it's like a road map... It joins up pieces; it's a way of getting from the start to the finish via all these places." 
Idea Generation and Material Consolidation: Tool Use and Intermediate Artefacts in Case Study of Journalistic Writing 13

In order to devise this route, the participant mentally proposed sub-structures to herself and worked through their implications. She described thinking through tradeoffs based on her evaluation of different structures on the one hand, and the ease with which they incorporated key ideas on the other.

The plan would always be written with pen and paper since this enabled her tools to be more 'instant' and so better support intensive thinking:

"I don't know, I think it's just more instant. I don't have to think about the typing [...] it's just the contact-hands-to-paper. The way you can just scribble something out, cross through it, get a new piece of paper. It just feels. I couldn't explain. The typing is different to the scrawling. It's just different."

When writing her plan, the participant placed the transcript on the desk, and flicked through looking for quotations. The process was exploratory, experimental and evaluative:

"I kind of had a thought that maybe might work and I was looking for the quote, to see if it worked."

In general, each note or phrase that she wrote on the plan would indicate a topic to be written about, and was written in a way that was personal to her:

"Yeah and even if they (somebody else) read it, they might get a different idea

of what I mean from reading my prompt, it does only work for me. [...] if

you're a complete stranger, say, the prompt will be almost meaningless."

Where appropriate, quotation reference numbers would be included to crossreference with the transcript.

The visual layout of the resulting plan was important. Not only did the order on the page determine the order that things would be written, but the participant used indentations to represent hierarchical levels of thematic structure (see Figure 3). She explained that this was done in order that the key point of each theme could be reviewed easily:

Researcher: "Does location of writing on the page have importance?"

Participant: "Yeah, in terms of relationship to the line before it and line after it, and how far over they are... top down, then left right aspect as well... Yeah it's like a Christmas tree shape.[...] The main section jumps out, you know, the least indented top line because that's the important thing and then underneath I can read further."

For ease of review, the plan would be kept to a single page, symbols (arrows, dashes, equals signs etc.) were used as a form of shorthand and to denote revisions to the structure, and occasionally colour was used to identify particularly important ideas.

"It's meant to be like an instant reference as opposed to something you read. [...] You want something instant. You don't want to spend time looking for the bit you are looking for. That's the only reason it's in note form with the arrows and things. Draws your eye, you know where you are!."

Once finished, the plan was rewritten to improve its legibility. 
14 Simon Attfield, UCL Interaction Centre, University College London.

s.attfield@cs.ucl.ac.uk, +44 (0) 2076795242 (tel), +44 (0) 2076795295 (fax).

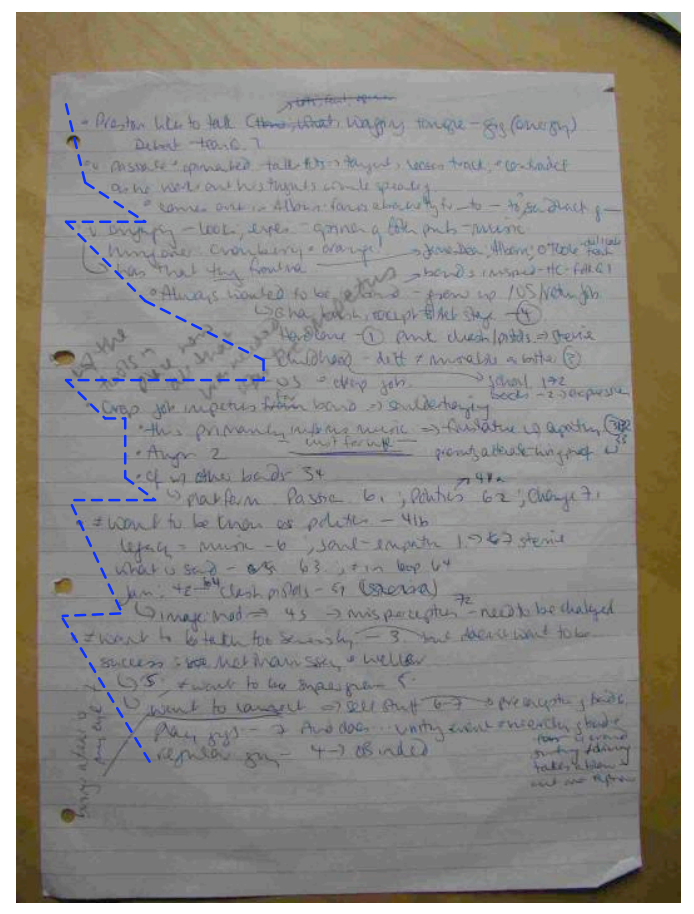

Figure 3. The plan. Dashed lines have been added to emphasise the hierarchical ('Christmas tree') structure.

\section{Discussion}

Although the solution space had been reduced by successive activities, exploration and experimentation were very evident during the initial generative phase of planning, articulated through the route-finding metaphor. Characteristic of generative thinking, the transcript was used to trigger ideas, perhaps many, which were then elaborated and evaluated comparatively. Once again, the generative phase featured intense engagement with source material in search of inspiration. Notably, at this time an emphasis was placed on the need for transparent tools. The strategy of documenting quotations by reference, and the low priority placed on legibility of the plan, further indicate the need for uninterrupted engagement with ideas.

The working document produced by the planning stage is the hierarchical plan. During planning, however, generating and consolidating were less clearly separated, although a move from one to the other was nevertheless evident. As planning progressed, and a structure increasingly emerged, so the need to design the plan in a way that would support the final stage of the work became more evident. In particular, the 'Christmas tree' shape indicating hierarchical structure was designed to 
Idea Generation and Material Consolidation: Tool Use and Intermediate Artefacts in Case Study of Journalistic Writing 15

support later ease of review. In a final, purely consolidatory stage the plan was rewritten for legibility.

Again, we see the need for ready-to-hand tools that do not interrupt the flow of ideas, and that support the user in exploiting spatial layout to facilitate reflection on the strengths and opportunities presented by the developing artefact (i.e. the plan). Extensive use was made of cross-referencing - another feature that would ideally be more seamlessly supported. In addition, there should be a smooth means of making a transition from a formative and provisional structure to a more clearly defined one.

\section{Writing}

In order to ensure the flow of writing, the participant wrote her piece from beginning to end. Writing was slow and considered, and could extend over several days. As she wrote, she experimented with and reflected on different ways of expressing things:

"It's like trying it on really. If you're sitting in a shop thinking about something you might quite like - that's kind of the thinking process - I like that red shirt, that looks quite nice. Then the writing it on the page is like trying it on and it might not fit and you get rid of it. That's the best way I can describe it."

The participant considered the choice of words and how they flowed together as important. She was keen to achieve a 'lyrical' style. When she had difficulty finding a word she wanted, she would either stop to use a thesaurus, or add a string of question marks as a visual marker so that she could continue writing.

"Because you are in the flow and you don't want to stop. And the question marks are an adjective - a word I can't think of right now."

The participant would also mark phrases that she wanted to reconsider later using bold formatting or capitals letters, and included alternative words and phrases that she needed to decide between.

She also considered it important to get facts and spellings right and would occasionally refer to stored e-mails, the Web, or dictionaries.

"Yeah, spelling peoples' names right, getting the chronology of things right. And not be misleading. Those (things) are quite important, so you always check them. Double check them absolutely. If I realise if there's any conflicting information I will ring up the press officer and double check them."

During writing, both the plan and the transcript were kept close by for reference. An important role for the plan was to act as an index so that she could flick through the transcript and quickly re-find quotations. If a quotation was short, she would copy it manually into her piece; otherwise, she would open an electronic version of the transcript, find the text using a string search, and transfer the quotation by copying and pasting. 
16 Simon Attfield, UCL Interaction Centre, University College London.

s.attfield@cs.ucl.ac.uk, +44 (0) 2076795242 (tel), +44 (0) 2076795295 (fax).

The plan was also used to guide the direction of the piece, but not extensively, only being referred to for direction when writing had stalled. If her writing was flowing naturally, then the plan would not be needed for direction.

"I use it when I get stuck... when I need the map I look at the map. Sometimes writing a piece is constant reference to the map, because it's not quite as fluid. Other pieces I get carried away and I've done A, B, C and D without realising I've done it. Nice when that happens."

The participant also described unplanned deviations that could occur when she was writing:

"You might find a different way when you get to this point, you get to a junction and realised that you don't have to go straight you can go left."

However, if a detour was subsequently evaluated negatively, she might backtrack and review the commitment from which it had been provoked.

"What's written on the page can dictate the movement of the piece, and if you feel the text on the page is moving you into where you don't want to go... you go back and change those things that would be moving you. Change back the direction."

The participant reported that, when she was over halfway through a piece, she would sometimes add a checklist of issues below her text that she wanted to cover before finishing. This would supersede her plan.

Writing was frequently interrupted by periods of reviewing and fixing, which varied in length and intensity. Edits were made to increase the clarity and impact of the text.

"... and every time you read through it, after every bit where you sort of run out of steam, go back and read through it always fixing something along the way, tightening, taking out sentences that don't need to be there, fixing stuff, adding things to make it more clear."

On returning to writing at the beginning of a new day, the participant would resume by re-reading the text before creating any new text-a task which would inevitably lead to editing. Reviewing could also occasionally lead to an entire rewrite.

The participant would sometimes delete sections of text from her draft, but would want to retain these in case they were needed later. And so she would cut and paste the text into a separate word processor document (referred to as a 'notes page'):

"Oh that's because sometimes I don't want to delete things because I sometimes wish I kept that sentence or those two words together. Like when I had my <band name> piece. I was commissioned to write it for 1800 words and I spoke about something, which I then decided I didn't need and then my editor rang me back and said can you do another 200 words? I just cut and pasted and just worded something and it fit. And I had my 200 words. It doesn't pay to delete things."

The participant tended to avoid printing drafts for reviewing due to cost and because she did not see this as essential. She found reading aloud from the screen a good substitute for reviewing on paper, and would only print when she wanted a break from the computer. 
Idea Generation and Material Consolidation: Tool Use and Intermediate Artefacts in Case Study of Journalistic Writing

Once a piece was complete, the participant would check its length and read through checking spellings and information, and ensuring that all her markers had been dealt with. She would ideally then read through the piece aloud, paying careful attention to what the text said rather then what she thought it said. When doing this, she would occasionally find she wanted to add further material and would return to the transcript for something appropriate.

The complete feature document would then be sent to the editor. Sub-editors and other newspaper staff would check the piece, write a stand-first and headline, and do any page setting or formatting required before publication.

\section{Discussion}

During writing, a distinction between generation and material consolidation can be seen in the difference between initial drafting and the final read-through with editing. However, as in planning, there appears to be a greater tendency to interleave modes. Some interruptions to text generation would be permitted in order to develop clarity and impact of the wording, but on other occasions the flow of writing would be maintained by using visual place-markers to indicate text for further consideration. The importance of enabling uninterrupted thought during writing is also indicated by the way that the plan was designed to support the easy retrieval of quotations.

During writing, the plan and transcript were kept close for easy reference. However, although the plan had been meticulously prepared, the text would be allowed to take its own direction. Like the use of the question sheet during the interview, the plan would only be used to provide guidance where the natural flow of writing had stalled. Related to this, and like planning, experimentation and evaluation of the results of these experiments played an important role during writing.

During writing, we see the importance of easy transitions between multiple documents: the main article, a to-do list, the plan, the transcript and a 'scratch pad' containing text that might be surplus to requirements. Some of these documents (e.g. the to-do list) are transitory whereas others (including the 'scratch pad') need to be kept, and ideally kept together with cross-referencing between documents.

\section{Summary}

The lifecycle of the research and writing task we observed had five distinct stages: 'establishing an idea', 'preparing for interview', 'interviewing', 'planning' and 'writing'. Each of these featured characteristically distinct phases that we have referred to as idea generation and material consolidation.

Although generation could occur in bursts, the need to achieve cognitive momentum during these periods was a frequent theme. Generation involved deep engagement with information (or people) and allowing this to spontaneously trigger new ideas and directions. The generative processes were typically intense, dependent upon external triggers for initiation, but establishing their own momentum and direction. These external triggers could be found through intense engagement with 
18 Simon Attfield, UCL Interaction Centre, University College London.

s.attfield@cs.ucl.ac.uk, +44 (0) 2076795242 (tel), +44 (0) 2076795295 (fax).

content materials in order to stimulate ideas (e.g. a hook, a theory, a way to begin) or through engagement with the interviewee.

Once idea generation began, it would achieve its own momentum to which interruptions were actively minimised. A characteristically low-cost and 'sketchy' approach was taken to recording ideas at the expense of a concern for presentation, coherence and detail, these being deferred (hence the two phase approach).

And during the interview and writing, prior to which painstaking planning had taken place, these plans were nevertheless subordinated to the ideas and directions occurring at the time. This need for momentum and focus, however, placed demands on the availability of information and the ease with which generated ideas could be recorded. Frustration could also arise when document coordination tasks interrupted the momentum, and consequently pen and paper were preferred during plan construction.

In contrast to this, material consolidation appeared to make fewer demands on sustaining momentum and engagement. Material consolidation generally provided the link between stages by configuring information into a working document designed to anticipate the demands of the next stage. Where the resource was to be used to support a further phase of generation, the need was that it should enable fluidity during this phase, and this usually meant being designed to support demands for easy information access. This meant that working documents were structured in a way to facilitate easy overview and navigation (the exception is the 'pitches' which were designed to convince the editor). The interview script was formatted into a single page, organized by theme and structured as a potential conversation. Important questions were highlighted and each edited to a single line. Similarly, the interview transcript was printed and its themes annotated and interesting quotations underlined. Also, the plan used indentations to represent thematic structure. Finally, in order to support easy idea cross-referencing, a numbering system was applied to the quotations.

\section{DISCUSSION}

The study we have reported maps out a sequence of activities engaged in by a journalist researching and writing a feature article. Specifically, it intentionally links processes to the way in which these place demands upon, and consequently configure, a working environment. As far as we are aware, this is the first account of its type of a writing assignment from conception to completion.

We focused on a single journalist and it is striking that, although she was engaged in an essentially unpredictable activity, her overall approach was systematic. As a general observation, this fits with Rowe's (1987) characterisation of design as involving sequential, systematic steps.

The distinction between idea generation and material consolidation emerged from the study and provided a convenient analytic frame for conceptualising interactions with the working environment. In relation to these ideas, the study elaborates on Csikszentmihalyi's (1996) point that creativity is enhanced by exercising such control, and Hewitt's (2005) conclusion that a key condition to creative work is the 
Idea Generation and Material Consolidation: Tool Use and Intermediate Artefacts in Case Study of Journalistic Writing 19

ability to create and modify external representations of interim results so that they can be used in further thinking about the problem.

During idea generation artefacts were created as initially sketchy, to be refined during consolidation phases. Further, refinements were generally intended to meet the cognitive demands of the next stage of the journalist's work. There are similarities here with Landay and Newman's (2000) study of Web designers and also some contrasts. Landay and Newman concluded that early website representations tend to be sketchy in order to quickly explore design ideas and avoid focussing on low level details too early in the process. However, within their reporting, there is evidence of cycles of what we have called generation and consolidation. In particular, they report hand sketched representations of structural and navigational variations being made "presentable" (on a computer) in order to show to a client; visual design variations were created by first creating quick sketches and then transforming these into mockups using a graphics/presentation software package; and finally, storyboards (which the paper suggests were sketched) were developed into computer-based walkthroughs for customers since these could appear aesthetically pleasing without looking "finished".

Whilst showing generalisability of the idea of cycles of idea generation and material consolidation, these observations also contrast with the current study in terms of the purpose of consolidation. With the exception of the pitch email, the journalist consolidated representations specifically to support the cognitive requirements of a further phase of generation. The Web designers, however, (and in common with email pitch) consolidated representations in order to support the communication of ideas and options, achieving consensus and promoting confidence. Hence, consolidation of representations can have social drivers as well as assisting personal cognition. These types of consolidation likely place different demands on tool supporting.

One further useful connection can be made with the Newman and Landay study. A recently recognized challenge for knowledge work research is to address the problem of fragmentation of information across multiple tools and organizational schemas that typically occurs due to wide range of available tools and technologies (Jones \& Maier 2003; Jones et al 2005). In the context of creative work, there have been proposals for system concepts that dissolve application boundaries (Hewitt 2005; Shneiderman, 1999). Landay and Newman (2000) echoed this concern. They found that, given the multiple representations used in the Web design process, designers expressed a wish for different representations to be tied together in a unified framework to help them keep track of project histories and support coherent project management.

A solution to this problem has been proposed in the form of Jones et al's (2005) Universal Labeller. This tool allows users to construct a structured to-do list associated with a project, and for each item to associate documentary results. This enables access to project documents from a single integrated, representation. Significantly, this idea extends beyond the traditional operating system design metaphor of a filing cabinet which represents associations between documents by hierarchically nested groupings.

The case study reported here supports this need for a representation integrating tool, but allows us to elaborates further on its form. The Universal Labeller represents working documents as contingent upon work activities, but where they form 
20 Simon Attfield, UCL Interaction Centre, University College London.

s.attfield@cs.ucl.ac.uk, +44 (0) 2076795242 (tel), +44 (0) 2076795295 (fax).

intermediate work products (as they frequently are), they also provide the resources for subsequent stages (and their documentary products). Therefore, a representational metaphor which echoes this workflow more completely would represent chains of document or document/activity sequences (see figure 1).

Within HCI an emphasis has been placed on the importance of enabling 'transparent' interaction (Hutchins et al 1986, Strong 1994, Winograd \& Flores, 1986). By this is meant designing systems such that users can interact with the semantics of their task without being unduly distracted by the acts of formulating commands and interpreting information. The current study qualifies this by emphasising the need for transparent interaction in creative endeavours specifically during periods of generation. These are the most cognitively demanding times in which the momentum is key to a successful outcome.

What is important during generative phases is flow, and the representation of information and configuration of tools to support that flow. Taking the current domain as an example, this has implications for the ability to coordinate multiple documents in order to promote visual availability (suggesting the need for multiple display devices), to structure and format documents to reflect the users' developing taskcentred concepts, priorities and understanding, and to support task-centred crossindexing of items for easy retrieval. In earlier sections (4.1, 4.2, etc.), we have highlighted particular requirements that emerge from considering each of the generative and consolidatory tasks in which the participating journalist engaged.

The case study presented here represents a rich scenario of productive creativity in the context of journalistic writing. It is a single case study, and might be regarded as therefore having limited generalisability. Nevertheless, we have related this idiographic case study to nomothetic (generalised) findings from others that focus on particular stages of the overall writing process, and also to more generalised requirements that have been articulated by others for tools to support creative activities (involving integration, transparency and overview). This case study provides a rich illustration of the detailed user activities over the entire writing process from ideas generation to delivery of the final article, highlighting particular ways in which documents need to be integrated (e.g. by cross-referencing, or by copying or moving material from one document to another); particular points in the writing process at which tool transparency is essential; and what kinds of overview are needed at particular stages of the process. As such, this case study complements previous work on tools to support writing as an integrated activity.

\section{ACKNOWLEDGMENTS}

We are grateful to the principal participant in this study for her contribution. This work was in part funded by EPSRC grant EP/D056268 ('Making Sense of Information') 
Idea Generation and Material Consolidation: Tool Use and Intermediate Artefacts in Case Study of Journalistic Writing

\section{REFERENCES}

Attfield S., Blandford A. \& Dowell J., 2003. Information seeking in the context of writing: a design psychology interpretation of the 'problematic situation'. Journal of Documentation, 59(4), 430-453.

Bereiter C. \& Scardamalia M., 1987. The Psychology of Written Communication. Hillsdale, New Jersey: Erlbaum.

Bonnardel N., 1999. Creativity in design activities: The role of analogies in a constrained cognitive environment. Creativity and Cognition, Loughborough, UK, 158-165.

Csikszentmihalyi M., 1996. Creativity. Harper-Collins, New York.

Flower L. \& Hayes J.R., 1981. A cognitive process theory of writing. College Composition and Communication, 32, pp. 365-387.

Glaser B. \& Strauss A., 1967. The discovery of grounded theory: Strategies for qualitative research. New York: Aldine de Gruyter.

Goel V. \& Pirolli P., 1992. The structure of design problem spaces. Cognitive Science, 16, pp. 395-429.

Haas C., 1989. Does the medium make a difference? Two studies of writing with pen and paper and with computers. Human Computer Interaction, 10, pp. 149-169.

Haas C., 1996. Writing technology: Studies on the materiality of literacy. Mahwah, N.J.: Lawrence Erlbaum Associates.

Hansen W. and Haas C., 1988. Reading and writing with computers: a framework for explaining differences in performance. Communications of the ACM, 31(9), pp. 1080-1089.

Hewett T., 2005. Informing the design of computer-based environments to support creativity. International Journal of Human-Computer Studies 63, pp. 383-409.

Hollan J., Hutchins E., \& Kirsh D., 2000. Distributed cognition: Toward a new foundation for human-computer interaction research. ACM Transactions on Computer-Human Interaction, 7(2), pp. 174-196.

Hutchins E.L., Hollan J.D. \& Norman D.A., 1986. Direct manipulation interfaces. In: Norman \& Draper (eds.), User Centered System Design., San Diego.

Jones W. \& Maier D., 2003. Personal Information Management Group Report. NSF IDM 2003 Workshop.

Jones W., Munat C., Bruce H. \& Foxley A., 2005. The Universal Labeler: Plan the Project and Let Your Information Follow. Proceedings of the 68th Annual Meeting of the American Society for Information Science and Technology (ASIST).

Lawson B., 1997. How designers think: The design process demystified, 3rd ed. Oxford, Butterworth-Heinemann.

Luthans, F. \& Davis, T. R. V. (1982) An Idiographic Approach to Organizational Behavior Research: The Use of Single Case Experimental Designs and Direct Measures. The Academy of Management Review, 7.3, pp. 380-391.

Neuwirth C. \& Kaufer D., 1989. The role of external representations in the writing process: Implications for the design of hypertext-based writing tools. Proceedings of Hypertext '89, pp. 319-341.

O'Hara K., Taylor A., Newman W. \& Sellen A., 2002. Understanding the materiality of writing from multiple sources. International journal of human-computer studies 56(3), pp. 269-305.

Rowe P., 1987. Design Thinking. MIT Press, Cambridge.

Schön D.A., 1983. The reflective practitioner: How professionals think in action. New York, Basic Books.

Sharples M., 1996. An account of writing as creative design. In: Levy C.M. \& Ransdell S. (eds.), The science of writing. New Jersey, Lawrence Erlbaum.

Shneiderman B., 1999. User interfaces for creativity support tools. In: Candy L. \& Edmonds E. (eds), Proceedings of the 3rd conference on Creativity \& cognition, pp. 15-21. 
22 Simon Attfield, UCL Interaction Centre, University College London.

s.attfield@cs.ucl.ac.uk,+44 (0) 2076795242 (tel), +44 (0) 2076795295 (fax).

Shneiderman B., 2000. Creating creativity: user interfaces for supporting innovation. ACM Transactions on Computer-Human Interaction 7(1), pp. 114-138.

Smith J., Weiss S. \& Ferguson G., 1987. A hypertext writing environment and its cognitive basis. Proceedings of Hypertext '87, University of North Carolina, Chapel Hill, pp. 195-214.

Strong G., 1994. New Directions in Human-Computer Interaction, Education, Research, and Practice, Drexel.

Taylor I.A., 1959. The nature of the creative process. In: P. Smith (Ed.), Creativity: An examination of the creative process, New York: Hastings House Publishers. pp. 51-82.

Winograd T. \& Flores F., 1986. Understanding Computers and Cognition - a new foundation for design. Norwood, N.J: Ablex.

Newman M.W. \& Landay J.A. 2000. Sitemaps, storyboards, and specifications: a sketch of Web site design practice. Proceedings of the conference on designing interactive systems: processes, practices, methods, and techniques. New York City, New York, United States. pp 263-274.

Sumner and Stolze

Belotti and Rogers 